\title{
LA TUTELA TRANSFRONTERIZA DE LOS DERECHOS DE LA PERSONALIDAD EN LA UNIÓN EUROPEA
}

\section{CROSS-BORDER PROTECTION OF PERSONALITY RIGHTS IN THE EUROPEAN UNION}

\author{
Marina Cedeño Hernán \\ Profesora Titular de Derecho Procesal \\ Universidad Complutense de Madrid \\ Instituto de Derecho Europeo e Integración Regional (IDEIR)
}

Recibido: 00.00.2010 / Aceptado: 00.00.2010
DOI: https://doi.org/10.20318/cdt.2021.5954

Resumen: Los litigios transfronterizos sobre vulneración de los derechos de la personalidad plantean importantes cuestiones jurídicas tanto en lo que respecta a la competencia internacional como al Derecho aplicable. La exclusión de esta materia del ámbito de aplicación del Reglamento Roma II relativo a la ley aplicable a las obligaciones extracontractuales confiere a la determinación de la competencia internacional una especial relevancia.

El apartado 2 del artículo 7 del Reglamento Bruselas I bis establece una regla especial de competencia en materia delictual o cuasi delictual, en favor del Estado en cuyo territorio se haya producido o se pueda producir el daño. La determinación de ese lugar no siempre resulta sencilla, en especial si el medio utilizado para la lesión del derecho de la personalidad es internet. En el presente trabajo se analiza la prolífica $\mathrm{y}$, a veces, controvertida jurisprudencia del TJUE sobre la determinación del lugar del daño ex artículo 7.2 del Reglamento Bruselas I bis y los nuevos criterios de competencia internacional creados por el Tribunal.

Palabras clave: competencia judicial internacional, derechos de la personalidad, Reglamento Bruselas I bis, Reglamento Roma II.

Abstract: Cross-border disputes over the rights of individuals raise important legal issues as regards both jurisdiction and applicable law. The exclusion of this matter from the scope of the Rome II Regulation on the law applicable to non-contractual obligations makes the determination of international jurisdiction particularly important.

Article 7(2) of the Brussels I-bis Regulation establishes a special rule of jurisdiction in matters of tort, delict, or quasi-delict, in favor of the State in whose territory the damage occurred or is likely to occur. Determining that place is not easy, especially if the medium used for the injury of the right is the Internet. This paper analyses the prolific and controversial case law of the ECJ on the interpretation of Article 7(2) of the Brussels I-bis Regulation and the new rules of international jurisdiction created by the Court.

Keywords: international jurisdiction, rights of the personality, Brussels I-bis Regulation, Rome II Regulation.

Sumario: I. Introducción. II. la ausencia de normas de conflicto uniformes en la Unión Europea. III. La falta de normas especiales de competencia en el Reglamento Bruselas I bis. IV. La determinación del «lugar del daño» como criterio de fijación de la competencia judicial internacional. 1.

* Este trabajo se enmarca dentro del proyecto de investigación «Hacia un proceso civil convergente con Europa: Hitos presentes y retos futuros» (PGC2018-094693-BI00), financiado por el Ministerio de Ciencia e Innovación. 
La regla de la ubicuidad. 2. La regla del mosaico. 3. Un nuevo fuero de competencia internacional: el centro de intereses de la persona física. A) La adaptación de la jurisprudencia al contexto de internet. B) La determinación del lugar del centro de intereses de la víctima. 4. La extensión del nuevo foro a las personas jurídicas: el centro de intereses de las personas jurídicas. 5. La competencia del tribunal del lugar del daño para decidir sobre acciones de rectificación o supresión de la información presuntamente lesiva. V. La Resolución del Instituto de Derecho Internacional sobre internet y la vulneración de la privacidad: ¿un posible modelo para el legislador de la Unión Europea? 1. El principio holístico, los criterios de fijación de la competencia internacional y el reconocimiento y ejecución de resoluciones extranjeras. 2. El Derecho aplicable: la lex fori y sus excepciones. VI. A modo de conclusión.

\section{Introducción}

1. La tutela transfronteriza de los derechos de la personalidad suscita cuestiones jurídicas complejas que requieren una solución clara y homogénea en la Unión Europea. Como premisa, hay que tener en cuenta que las intromisiones ilegítimas en los derechos al honor, a la intimidad y a la propia imagen se producen en la mayoría de los casos por la colisión de dos derechos fundamentales, previstos tanto en la Carta de Derechos Fundamentales de la Unión Europea (en adelante, CDFUE) como en el Convenio Europeo de Derechos Humanos (en adelante, CEDH). De un lado, la libertad de expresión y de información, previstas en el artículo 11 de la CDFUE y en el artículo 10 del CEDH. De otro lado, el respeto a la vida privada y familiar, así como a la reputación, contemplados en los artículos 7 y 8 de la CDFUE y en el artículo 8.1 del CEDH.

2. La atribución del carácter de fundamentales tanto a los derechos al honor, a la intimidad y a la propia imagen como a la libertad de expresión y al derecho a la información con los que en muchas ocasiones entran en conflicto condiciona no solo el derecho aplicable sino también el reconocimiento y ejecución de las decisiones judiciales por su incidencia sobre el orden público de cada Estado.

3. En todos los países de nuestro entorno se reconocen y protegen estos derechos, pero su configuración y el alcance de su protección difieren de unos a otros. Los ordenamientos han de procurar mantener un difícil equilibrio entre el amparo de los derechos de la personalidad y la garantía de la libertad de expresión. En función del momento y del lugar se puede dar prioridad a alguno de los derechos en liza y, en consecuencia, pueden variar las decisiones sobre la posible vulneración del derecho al honor, a la intimidad o a la propia imagen. No resulta, por ello, extraño que los perjudicados suelan decantarse por presentar la demanda ante los tribunales de aquellos Estados que den mayor peso a la protección de la intimidad y la reputación frente a la libertad de expresión, pese a que la conexión con esos Estados sea más débil que con otros territorios.

4. Nos encontramos en un momento de extraordinaria expansión de las tecnologías de la información y comunicación (en adelante, TICs) y, en especial, de internet como vehículo de transmisión e intercambio de todo tipo de información. En esta era digital es posible una difusión potencialmente universal de contenidos difamatorios, así como cierta deslocalización en algunas de las actividades lesivas con la consiguiente dificultad para delimitar la ubicación geográfica del daño al honor, a la intimidad o a la propia imagen. Se trata, por ello, de un sector de los ilícitos civiles que tiene una evidente dimensión transnacional.

\section{La ausencia de normas de conflicto uniformes en la Unión Europea.}

5. Es precisamente el potencial alcance supranacional de la lesión a los derechos de la personalidad el que hace necesario, como punto de partida, una regulación unitaria en cuanto a la ley aplicable con independencia del Estado ante el que se haya planteado el litigio. Las normas de conflicto vigentes 
en cada uno de los Estados miembros revelan una diversidad de criterios que es fuente de incertidumbre jurídica. Los factores de conexión que se tienen en cuenta en los Estados son múltiples: la sede del editor, el lugar donde se publicó o editó el producto, el lugar donde se difundió y se dio a conocer a terceros, el lugar donde la víctima goza de notoriedad que, en principio, coincide con su residencia habitual y no han faltado las soluciones en favor de la víctima que permiten a ésta elegir entre varias opciones posibles ${ }^{1}$.

6. La unificación de las normas de conflictos de leyes vigentes en los Estados miembros facilitaría la previsibilidad del resultado de los litigios, la libre circulación de resoluciones judiciales y, en definitiva, la seguridad jurídica.

7. En esta línea, los textos preparatorios del Reglamento 864/2007 del Parlamento Europeo y del Consejo, de 11 de julio de 2007, relativo a la ley aplicable a las obligaciones extracontractuales (Reglamento Roma II), sí contenían reglas especiales para los casos de daños a los derechos de la personalidad. La propuesta inicial, contenida en el artículo 7 del Anteproyecto de Propuesta de Reglamento de 3 de mayo de $2002^{2}$, utilizaba como criterio de conexión la residencia habitual de la víctima porque de esta forma se aseguraba la aplicación de la ley más estrechamente vinculada al caso. Esta propuesta fue objeto de importantes críticas, en buena medida provenientes de los lobbies del sector de los medios de comunicación, con argumentos algo peregrinos como que no es siempre fácil conocer la residencia habitual de las personalidades famosos o que la combinación entre normas de conflicto y normas de competencia podría conducir a una situación en la que los tribunales del Estado de la sede del editor tuvieran que condenar a éste en aplicación de la ley de residencia habitual de la víctima, pese a que no se hubieran infringido las normas vigentes en el Estado de la sede del editor y ningún ejemplar de la publicación se hubiera difundido en el Estado de residencia de la víctima ${ }^{3}$.

8. La propia Comisión reconoció que el peso de las críticas le hicieron modificar su planteamiento inicial y en su Propuesta de Reglamento de 22 de julio de 2003 resulta evidente el cambio total de óptica. El artículo 6, con términos bastante confusos, remite, en primer lugar, a la regla general del artículo 3 de la Propuesta, es decir, a la ley del país donde se produce o amenaza con producirse el daño a menos que ambas partes tengan su residencia habitual en otro Estado o que el litigio presente vínculos más estrechos con otro Estado. Esta regla general, ya de por sí poco concreta, se completa con otra específica para las obligaciones extracontractuales que resulten de la violación de la intimidad o de los derechos de la personalidad que remite a la ley del foro «cuando la aplicación de la ley designada por el artículo 3 sea contraria a los principios fundamentales del foro en materia de libertad de expresión e información».

9. Resulta llamativo que, en esta ocasión, se resalten los principios fundamentales en materia de libertad de expresión e información y se olvide los derechos no menos fundamentales al honor, a la intimidad o a la propia imagen. En cualquier caso, esa regla especial resultaba del todo inútil porque la Propuesta de Reglamento ya recogía una cláusula de orden público, en su artículo 22, que permitía excluir la aplicación de la ley designada si resulta «manifiestamente incompatible con el orden público del foro» ${ }^{4}$.

\footnotetext{
${ }^{1}$ Una visión general de la diversidad de las normas de conflicto vigentes en los Estados de la Unión Europea puede verse en la «Propuesta de Reglamento relativo a la ley aplicable a las obligaciones extracontractuales (Roma II)», presentada por la Comisión, de 22 de julio de 2003, COM(2003) 427 final, pp. 18 y sigs.

2 Documento COM (2003) 427 final.

${ }^{3}$ Estas críticas se recogen en la explicación sobre el contenido del artículo 6 de la «Propuesta de Reglamento relativo a la Ley aplicable a las obligaciones extracontractuales», presentada por la Comisión con fecha 22 de julio de 2003 , pág. 19.

${ }^{4}$ En este sentido, E. TORRALBA MENDIOLA, «La difamación en la era de las comunicaciones: ¿nuevas? Perspectivas de Derecho Internacional Privado Europeo», en InDret. Revista para el análisis del Derecho, Enero de 2012, pág. 7, afirma: «Puesto que los derechos en juego en estos casos son en la generalidad de los Estados miembros de la UE derechos fundamentales y están además recogidos en el CEDH no parece que pudiera haber ninguna duda de que si la ley designada como aplicable por la regla general condujera a un resultado que llevara a la vulneración de derechos considerados esenciales en los Estados miembros (con independencia de que la forma de protegerlos en cada uno de ellos sea diferente) sus tribunales dejarían de aplicar el Derecho extranjero para resolver el supuesto de acuerdo con la ley del foro».
} 
10. El mismo camino siguió el texto aprobado por el Parlamento Europeo sobre la Propuesta de Reglamento que, en su artículo 5, remitía a la Ley del país donde se produzcan los elementos más significativos del hecho dañoso, aunque era mucho más explícita que la Comisión a la hora de concretar qué debe entenderse por lugar del daño 5 .

11. La imposibilidad de llegar a una solución de consenso sobre la ley aplicable a las violaciones de los derechos relacionados con la personalidad tuvo como consecuencia la supresión de la norma específica sobre esta materia en la Posición Común del Consejo ${ }^{6}$.

12. Finalmente, el Reglamento Roma II no solo no contiene una norma especial relativa a la ley aplicable a las infracciones de los derechos de la personalidad sino que excluye expresamente de su ámbito de aplicación «las obligaciones extracontractuales que se deriven de la violación de la intimidad o de los derechos relacionados con la personalidad, en particular la difamación» (artículo 1.2,g). No es posible, por tanto, buscar una solución al problema de la ley aplicable a las demandas de responsabilidad civil derivadas de la vulneración de los derechos de la personalidad ni siquiera en las normas generales del Reglamento?

13. La ausencia de unas normas de conflicto uniformes en la Unión Europea no es un buen punto de partida para dar respuesta a la cuestión fundamental en la que se centrará este estudio: la determinación de la competencia judicial internacional en las demandas derivadas de la violación de los derechos de la personalidad, en especial en los casos de difamación.

\section{La falta de normas especiales de competencia en el Reglamento Bruselas I bis.}

14. La determinación de la competencia judicial internacional en los litigios relativos a la responsabilidad extracontractual derivada de la vulneración de los derechos de la personalidad reviste una

\footnotetext{
${ }^{5}$ Resolución legislativa del Parlamento Europeo sobre la propuesta de Reglamento del Parlamento Europeo y del Consejo relativo a la ley aplicable a las obligaciones extracontractuales ("Roma II") (COM(2003)0427 - C5-0338/2003 2003/0168(COD)). El artículo 5, bajo el rótulo «Violación de la intimidad y del los derechos de la personalidad» dispone: «1. Por lo que se refiere a la ley aplicable a la obligación extracontractual que resulta de una violación de la intimidad o de los derechos de la personalidad, se aplicará la ley del país en el que ocurran o puedan ocurrir el elemento o los elementos más significativos del daño o del hecho dañoso. Cuando la violación tenga su origen en una publicación impresa o en una radiodifusión, debe considerarse que el país en el que ocurran o puedan ocurrir el elemento o los elementos más significativos del daño, es el país al que se destina principalmente una publicación o radiodifusión o, si ello no estuviese claro, el país en el que se ejerce el control editorial, y debe aplicarse la ley de dicho país. El país al que se destina una publicación o radiodifusión deberá determinarse especialmente por la lengua de la publicación o radiodifusión, o el volumen de ventas o los índices de audiencia en un país específico en relación proporcional con las cifras totales de ventas o de audiencia, o una combinación de estos factores. Esta disposición se aplicará, mutatis mutandis, a las publicaciones en Internet y otras redes electrónicas. 2. La ley aplicable al derecho de respuesta o a las medidas equivalentes y a toda medida preventiva o todo interdicto prohibitorio contra un editor de prensa escrita o un organismo de radiodifusión respecto del contenido de una publicación o radiodifusión es la del país donde el editor de prensa escrita u organismo de radiodifusión tenga su residencia habitual. 3. El apartado 2 se aplicará también a las violaciones de la intimidad o de los derechos de la personalidad derivadas del tratamiento de datos personales».

La misma propuesta se recogió en el artículo 7 de la Resolución legislativa del Parlamento Europeo respecto de la Posición Común del Consejo con vistas a la adopción del Reglamento del Parlamento Europeo y del Consejo relativo a la ley aplicable a las obligaciones extracontractuales ("ROMA II") (9751/7/2006 - C6-0317/2006 -2003/0168 (COD)).

${ }^{6}$ Posición Común (CE) n o 22/2006, de 25 de septiembre de 2006, aprobada por el Consejo de conformidad con el procedimiento establecido en el artículo 251 del Tratado constitutivo de la Comunidad Europea, con vistas a la adopción de un Reglamento del Parlamento Europeo y del Consejo relativo a la ley aplicable a las obligaciones extracontractuales (ROMA II).

${ }^{7}$ No obstante, resulta tan evidente que el problema no se solucionará por la vía de excluirlo del Reglamento que el propio legislador europeo parece dejar la puerta abierta a una regulación futura cuando en su artículo 30.2, bajo el rótulo «cláusula de revisión», insta a la Comisión a presentar al Parlamento Europeo, al Consejo y al Comité Económico y Social Europeo un estudio sobre la situación en el ámbito de la ley aplicable a las obligaciones extracontractuales derivadas de la violación de la intimidad y de los derechos relacionados con la personalidad. Este informe se publicó en febrero de 2009 y en él quedan patentes las discrepancias entre los ordenamientos de los Estados en la regulación de esta cuestión.
} 
particular complejidad. En la Unión Europea, el Reglamento Bruselas I bis ${ }^{8}$, norma fundamental en la materia, no contiene un fuero de competencia específico relativo a los ilícitos civiles derivados de la vulneración del derecho al honor, a la intimidad o a la propia imagen, a diferencia de lo que sucede en otros ámbitos de la responsabilidad extracontractual necesitados también de un tratamiento especial.

15. La ausencia de fueros especiales de competencia unida a la falta de armonización del Derecho sustantivo y de las normas de conflicto suscita importantes dificultades en la litigación internacional. En este contexto, la delimitación clara de la competencia judicial internacional resulta esencial, pues serán las normas de Derecho internacional privado del Estado competente las que determinarán el Derecho sustantivo aplicable, así como los límites a la eventual aplicación de normas sustantivas extranjeras si ha de entrar en juego el orden público estatal. No cabe duda, por tanto, de que el binomio forum-ius resulta crucial en este ámbito9.

16. En ausencia de un régimen especial de competencia internacional en las acciones derivadas de la vulneración de los derechos de la personalidad, se aplicarán las normas generales del Reglamento Bruselas I bis en materia de responsabilidad extracontractual.

17. El artículo 7.2 del Reglamento Bruselas I bis atribuye a los tribunales «del lugar donde se hubiera producido o pueda producirse el hecho dañoso» la competencia para conocer de la «materia delictual o cuasi delictual». Nos encontramos ante un foro de ataque que ofrece al demandante una alternativa al fuero general del domicilio del demandado, previsto en el artículo 4, cuando el lugar del daño se encuentre en un Estado miembro de la Unión.

18. Ambos fueros tienen carácter subsidiario respecto de la «prórroga de la competencia», prevista en los artículos 23 y 24 del Reglamento Bruselas I bis, que permite mediante el juego de la autonomía de la voluntad de las partes atribuir la competencia a los órganos jurisdiccionales de un determinado Estado.

19. En materia de responsabilidad extracontractual en general, y en el de los ilícitos civiles derivados de la vulneración de los derechos de la personalidad en particular, el juego de la sumisión expresa es prácticamente inexistente. Resulta evidente que este tipo de responsabilidad surge sin que exista una relación previa entre las partes y, por tanto, no habrá posibilidad de un acuerdo de sumisión expresa previo al nacimiento de la controversia. Una vez surgido el problema, las partes no suelen estar motivadas para hacer un pacto de atribución de la competencia, aunque, al menos en teoría, ese acuerdo sería válido y eficaz. En definitiva, ni a priori ni a posteriori la sumisión expresa suele ser una herramienta útil para fijar el tribunal con competencia internacional.

20. No sería, sin embargo, descartable en este ámbito la eficacia de la sumisión tácita. Si el demandante presenta su demanda ante los tribunales de un determinado Estado y el demandado comparece ante los tribunales de ese Estado sin impugnar su competencia judicial internacional, está manifestando implícitamente su voluntad de que el asunto se someta al conocimiento de esos tribunales. Esta "prórroga de la competencia» no plantea especiales dificultades en los casos de vulneración de los derechos de la personalidad.

21. En defecto de sumisión, quien haya sufrido o pretenda evitar sufrir un daño puede elegir entre presentar la demanda ante los tribunales del Estado donde el demandado tenga su domicilio o ante los tribunales del lugar donde se haya producido o pueda producirse el daño. El domicilio del demandado es el criterio básico de atribución de competencia internacional en la mayoría de los ordenamientos

\footnotetext{
${ }^{8}$ Reglamento 1215/2012 del Parlamento Europeo y del Consejo de 12 de diciembre de 2012, relativo a la competencia judicial, el reconocimiento y la ejecución de resoluciones judiciales en materia civil y mercantil.

${ }^{9}$ En este sentido, C. I., Cordero Álvarez, Litigios internacionales sobre difamación y derechos de la personalidad, Ed. Dykinson, Madrid, 2015, p. 82.
} 
procesales europeos. Se trata del «fuero de defensa» por excelencia que tiene la ventaja de permitir un alto grado de previsibilidad en la fijación del Estado miembro a cuyos tribunales se les atribuye la competencia internacional.

22. Este fuero general sí puede resultar adecuado para determinar el tribunal competente en las demandas basadas en la lesión de los derechos de la personalidad y, además, permitirá aunar en un único proceso y ante un único tribunal la reclamación por todos los daños que se hubieran producido, aunque se hubieran materializado en Estados distintos. Se facilita, pues, la concentración de las acciones ante los tribunales de un único Estado, lo cual resulta especialmente útil cuando el medio utilizado para la lesión del derecho al honor, a la intimidad o a la propia imagen tiene un alcance casi universal como es internet $^{10}$. Y, desde luego, no resulta tampoco desdeñable la ventaja que supone para la ejecución de la eventual sentencia condenatoria, pues, por lo general, el demandado tendrá sus bienes en el territorio donde se encuentre su domicilio.

23. Sin embargo, cuando el medio utilizado para la lesión de los derechos de la personalidad es el entorno virtual se pueden plantear ciertas dificultades en la práctica para la determinación del domicilio del demandado. Las actividades desarrolladas mediante el uso de internet permiten en ciertos casos el anonimato y es evidente que eso dificultará conocer la identidad del responsable o la localización de su domicilio.

24. Esta indeterminación puede suponer un problema no solo para la fijación del fuero general de competencia sino también para la aplicación del propio sistema de competencia internacional establecido en el Reglamento Bruselas I bis ${ }^{11}$. Si el demandado no está domiciliado en un Estado miembro solo se aplicará en parte el Reglamento y, en lo que ahora interesa, no será de aplicación el fuero de competencia en materia de responsabilidad extracontractual del artículo 7.2.

25. Sobre este particular tiene mucha relevancia la doctrina sentada por el Tribunal de Luxemburgo en la STJUE de 15 de marzo de 2012, asunto $G$ c. Cornelius de Visser (C-292/10), ECLI:EU:C:2012:142 ${ }^{12}$. El demandante ejercita una acción de responsabilidad extracontractual por la gestión de un sitio de internet en el que se publicaron sin su autorización unas fotografías frente a un demandado que es probablemente ciudadano de la Unión, pero que se halla en paradero desconocido. El órgano jurisdiccional remitente de la cuestión prejudicial pregunta, entre otras cosas, cómo deben interpretarse los términos «no estuviere (el demandado) domiciliado en un Estado miembro» que, en virtud del artículo 4, apartado 1, del Reglamento 44/2001, condicionan la aplicación de las normas de competencia nacionales en lugar de las normas uniformes de dicho Reglamento.

26. El TJUE estima que solo cabe la aplicación de las reglas nacionales en lugar de las reglas uniformes de competencia «si el órgano jurisdiccional que conoce del asunto dispone de indicios probatorios que le permitan llegar a la conclusión de que el demandado, ciudadano de la Unión no domiciliado en el Estado miembro de dicho órgano jurisdiccional, está efectivamente domiciliado fuera del territorio de la Unión». Si no concurren estos «indicios probatorios», la competencia internacional del órgano jurisdiccional de un Estado miembro «se establece, con arreglo al Reglamento $n^{\circ} 44 / 2001$, cuando se cumplen los requisitos de aplicación de alguna de las reglas de competencia establecidas por dicho Reglamento, y entre ellas, en particular, la de su artículo 5, número 3, relativa a la materia delictual o cuasidelictual $\gg^{13}$.

\footnotetext{
${ }^{10}$ Cfr., C. I. Cordero Álvarez, Litigios internacionales..., cit., p. 98.

${ }^{11}$ El domicilio del demandado no es solo un fuero de competencia sino también el criterio básico para delimitar el ámbito espacial de aplicación del sistema de competencia judicial internacional regulado en el Reglamento Bruselas I bis. Así, el artículo 6 del Reglamento dispone: «Si el demandado no está domiciliado en un Estado miembro, la competencia judicial se regirá, en cada Estado miembro, por la legislación de ese Estado miembro, sin perjuicio de lo dispuesto en el artículo 18, apartado 1, el artículo 21, apartado 2, y los artículos 24 y 25. 2».

${ }^{12}$ Un comentario sobre la misma puede verse en C. I. CoRDERo Álvarez, «Infracción de derechos de la personalidad por publicación de fotografías en internet», en Revista Española de Derecho Internacional, vol. LXIV, 2012, págs. 221 a 224.

${ }^{13}$ Una interpretación similar había hecho con anterioridad el mismo Tribunal en la STJUE de 17 de noviembre de 2011,
} 
27. La aplicación de las reglas uniformes de competencia «es conforme con el imperativo de seguridad jurídica y con el objetivo de dicho Reglamento consistente en reforzar la protección jurídica de las personas que tienen su domicilio en la Unión, permitiendo al mismo tiempo al demandante determinar fácilmente el órgano jurisdiccional ante el cual puede ejercitar una acción y al demandado prever razonablemente ante qué órgano jurisdiccional puede ser demandado».

28. El TJUE hace una interpretación claramente favorable a la prevalencia de la normativa europea sobre las normas nacionales de competencia judicial internacional y, aunque referida al Reglamento 44/2001, esta doctrina resulta aplicable en el nuevo marco normativo del Reglamento Bruselas I bis que, en este punto, reproduce la misma regulación que su antecesor. En consecuencia, pese a que no se pueda determinar con exactitud el domicilio del demandado, nacional de un Estado de la Unión, se podrá aplicar el fuero de competencia en materia de responsabilidad extracontractual siempre que no existan «indicios probatorios» de que el demandado está efectivamente domiciliado en un Estado no miembro de la Unión Europea.

\section{La determinación del «lugar del daño» como criterio de fijación de la competencia judicial internacional}

29. El criterio principal del Reglamento Bruselas I bis en materia de obligaciones extracontractuales se encuentra en el artículo 7.2 en cuya virtud los domiciliados en un Estado miembro podrán ser demandados en otro Estado miembro «en materia delictual o cuasidelictual ante el tribunal del lugar donde se haya producido o pueda producirse el hecho dañoso» ${ }^{14}$.

30. Este fuero de competencia tiene su fundamento en lo que la doctrina ha denominado «principio de proximidad» en la medida en que el tribunal del lugar del daño será el más cercano a los hechos que motivan el litigio y podrá llegar a una decisión de fondo más efectiva. Se trata de un fuero de competencia alternativo al del domicilio del demandado por razón de la estrecha conexión entre el órgano jurisdiccional y el litigio en cuestión y porque además facilita la buena administración de justicia.

asunto Hypoteční banka (C-327/10), ECLI:EU:C:2011:745. Esta Sentencia trae causa de un proceso de reclamación de cantidad derivada de un crédito hipotecario frente a un consumidor cuyo domicilio se desconoce. El Tribunal de Luxemburgo afirma lo siguiente: «A la vista de lo anteriormente señalado, procede considerar que, en una situación como la controvertida en el litigio principal, en la que un consumidor que ha firmado un contrato de préstamo inmobiliario de larga duración, el cual establece la obligación de informar a la otra parte contratante de todo cambio de domicilio, renuncia a su domicilio antes de la interposición de una acción en su contra por incumplimiento de sus obligaciones contractuales, los tribunales del Estado miembro en el que se encuentre el último domicilio conocido del consumidor son competentes, en virtud del artículo 16, apartado 2 , del Reglamento $n^{\circ} 44 / 2001$, para conocer de dicha acción en caso de que no logren determinar, con arreglo al artículo 59 del mismo Reglamento, el domicilio actual del demandado ni dispongan tampoco de indicios probatorios que les permitan llegar a la conclusión de que el demandado está efectivamente domiciliado fuera del territorio de la Unión». En apoyo de esta postura, el Tribunal argumenta que «...al privilegiar la aplicación de las reglas uniformes establecidas en el Reglamento ${ }^{\circ}$ 44/2001 frente a las divergentes reglas nacionales, dicha solución permite evitar que el hecho de que sea imposible localizar el domicilio actual del demandado impida determinar el órgano jurisdiccional competente y prive de este modo al demandante de su derecho a la tutela judicial. Tal situación podría producirse concretamente en un supuesto como el del litigio principal, en el que un consumidor que, en virtud del artículo 16, apartado 2, de dicho Reglamento, debería ser demandado ante los tribunales del Estado miembro en el que está domiciliado, renuncia a su domicilio antes de que se interponga la acción en su contra».

En este caso, no solo se considera aplicable el sistema de competencia internacional del Reglamento, sino también el fuero especial en materia de consumidores que remite al domicilio del consumidor, entendiendo por tal el último domicilio conocido. Esta doctrina resulta plenamente aplicable en el marco del Reglamento Bruselas I bis que es idéntico en este aspecto al Reglamento 44/2001.

${ }^{14}$ En múltiples Sentencias, el TJUE ha afirmado que el concepto de «materia delictual o cuasidelictual» requiere una interpretación autónoma con el fin de garantizar una aplicación uniforme del precepto en todos los Estados. El Tribunal de Luxemburgo ha manifestado que nos encontramos ante un fuero de carácter subsidiario y residual que comprende «toda demanda que se dirija a exigir responsabilidad de un demandado y que no esté relacionada con la materia contractual». Esta doctrina se expone con claridad en la Sentencia de 27 de septiembre de 1988, asunto Kalfelis c. Banco Schröder (C-189/87), ECLI:EU:C:1988:459. 
31. En este sentido, el Considerando 16 del Reglamento Bruselas I bis dispone « La existencia de una estrecha conexión debe garantizar la seguridad jurídica y evitar la posibilidad de que una persona sea demandada ante un órgano jurisdiccional de un Estado miembro que no hubiera podido prever razonablemente. Este aspecto reviste particular importancia en relación con los litigios relativos a obligaciones no contractuales derivadas de vulneraciones del derecho a la intimidad y de los derechos de la personalidad, incluida la difamación».

32. El problema que plantea la aplicación de esta regla es el de la concreción del lugar donde se ha producido el daño. En muchas ocasiones, la determinación de ese vínculo será una cuestión puramente fáctica que no requiere de una especial hermenéutica. Sin embargo, no resulta extraño que se produzca una disociación entre el lugar de origen del daño, es decir, donde se produjo el hecho causal del daño, y el lugar del resultado, es decir, donde se ha producido la lesión o intromisión en el bien jurídico protegido. Tampoco han faltado casos en los que la conducta y/o el resultado dañoso se pueden localizar en varios Estados. En estas situaciones, la concreción del forum delicti commissi se torna mucho más compleja.

33. Es precisamente en el ámbito de los derechos de la personalidad donde nos podemos encontrar los ejemplos más claros de dificultades a la hora de concretar el lugar del daño. Cuando el medio empleado para difundir la información lesiva tiene un alcance potencialmente global, como es el caso de internet, el lugar del daño tiende a deslocalizarse por la disociación entre la conducta de origen y la materialización del daño o por la concurrencia de una pluralidad de daños manifestados en distintos Estados. Se trata de un problema que no se puede calificar, ni mucho menos, de excepcional, dado que en un mundo globalizado como el actual buena parte de las actividades lesivas del derecho al honor, a la intimidad o a la propia imagen tienen lugar por la publicación y difusión de informaciones o imágenes lesivas en el medio digital.

34. Situaciones como la que se acaba de describir son fuentes de inseguridad jurídica porque el fuero de competencia internacional del Reglamento Bruselas I bis no es suficiente por sí solo para aclarar a qué Estado corresponde conocer de un asunto. Se hace necesaria, pues, una labor interpretativa a cargo del Tribunal de Justicia de la Unión Europea que consiga un doble objetivo: garantizar el derecho a la tutela judicial efectiva tanto de la víctima como del causante de la lesión del derecho al honor, a la intimidad o a la propia imagen y también asegurar la previsibilidad del tribunal competente.

\section{La regla de la ubicuidad}

35. La primera resolución en la que el Tribunal de Justicia tuvo que pronunciarse acerca de la interpretación del fuero del lugar del daño en un supuesto de disociación entre la conducta lesiva y el resultado dañoso es la Sentencia de 30 de noviembre de 1976, asunto Mines de Potasse (C-21/76), ECLI:EU:C:1976:166.

36. Los hechos que están en la base del litigio en el que se inscribe esta Sentencia no tienen que ver con la lesión de los derechos de la personalidad, sino con un caso de daños al medio ambiente por contaminación de las aguas, en el que la conducta de origen, consistente en unos vertidos de residuos salinos, y el resultado dañoso, manifestado en la contaminación de cultivos hortícolas, se sitúan en diferentes Estados de la Unión Europea. En estas circunstancias, el Gerechtshof (Tribunal de Apelación) de La Haya planteó al Tribunal de Justicia la cuestión de dónde debía entenderse producido el daño a efectos de determinar el tribunal competente.

37. El Tribunal de Justicia comienza resaltando que los fueros especiales de competencia internacional enumerados en el entonces Convenio de Bruselas constituyen alternativas al foro general del domicilio del demandado y se justifican por la conexión particularmente estrecha entre el litigio y el órgano jurisdiccional. En relación con el supuesto concreto planteado, el Tribunal estima que tanto el 
lugar del hecho causante como el lugar donde se materializa el daño pueden constituir, según los casos, una conexión relevante desde el punto de vista de la competencia judicial. La responsabilidad delictual o cuasidelictual solo surge cuando pueda establecerse un nexo causal entre el daño y el hecho que lo origina y, teniendo en cuenta la estrecha relación entre los distintos elementos constitutivos de la responsabilidad, no parece adecuado optar por uno de los puntos de conexión y excluir el otro.

38. El Tribunal de Justicia recurre a la «gran diversidad de tipos de responsabilidad» que pueden englobarse dentro de la materia delictual o cuasidelictual como apoyo de su decisión, pues entiende que, según las circunstancias de cada caso, puede ser útil desde el punto de vista de la prueba y de la sustanciación del proceso acudir a uno u otro de los puntos de conexión.

39. La imposibilidad de decantarse a priori por una de las dos opciones resulta abonada por la consideración de que si se eligiera con carácter exclusivo el lugar del hecho causante, muchas veces éste coincidiría con el fuero del domicilio del demandado, con lo que ese fuero especial perdería todo su efecto útil. Y, por el contrario, si se eligiera únicamente el lugar donde se ha materializado el daño «ocasionaría, en los casos en que el lugar del hecho causante no coincida con el domicilio de la persona responsable, la exclusión de una conexión apropiada con la competencia de un órgano jurisdiccional particularmente próximo a la causa del daño».

40. La conclusión que se deriva de esta argumentación es que «lugar donde se hubiere producido el hecho dañoso» debe interpretarse en el sentido de que se reconozca al demandante la opción de ejercitar su acción, bien en el lugar donde se haya materializado el daño, bien en el lugar en el que se haya producido el hecho causante ${ }^{15}$.

41. La decisión adoptada por el Tribunal de Justicia se aparta de la propuesta por el Abogado General en sus Conclusiones, presentadas el 10 de noviembre de 1976, en las que manifestó que tanto la letra como el espíritu de la norma se oponen a una solución cumulativa que deje al demandante la elección entre el tribunal del lugar del comportamiento y el del lugar de manifestación del daño. No es conforme con la letra porque el artículo 5.3 del Convenio de Bruselas se refiere al «tribunal del lugar» en el que se hubiera producido el hecho dañoso y, por tanto, debe ser «un solo tribunal y un solo lugar», excluyendo la eventualidad de que la competencia para conocer de un mismo evento dañoso se atribuya a una pluralidad de tribunales. Y no es conforme con el espíritu porque la finalidad de la normativa común es «realizar una distribución de la competencia internacional entre los distintos Estados según un criterio distributivo, para limitar y no ampliar la extensión de la competencia de cada uno de ellos donde ya exista un fundamento objetivo para atribuir la competencia a otro» ${ }^{16}$.

42. En todo caso, la solución salomónica por la que se decanta el Tribunal de Justicia en la Sentencia Mines de Potasse no resulta la más idónea para los casos de vulneración de los derechos de la personalidad ni en general para los litigios por daños localizados en varios Estados. Así, en los supuestos de publicaciones difamatorias, en especial en el entorno virtual, nos encontraremos con una multitud de tribunales potencialmente competentes conforme al fuero del lugar del daño ${ }^{17}$. No resulta, por ello, extraño que el Tribunal de Justica haya matizado su doctrina en posteriores resoluciones.

\footnotetext{
${ }^{15}$ Un amplio estudio sobre el fundamento y las implicaciones de la tesis de la ubicuidad puede verse en A. L., CALvo CAravaca y J. Carrascosa GonzÁlez, «El Derecho Internacional Privado de la Unión Europea frente a las acciones por daños anticompetitivos», en Cuadernos de Derecho Transnacional (Octubre 2018), Vol. 10, No 2, pp. 86 y sigs.

${ }^{16}$ El Abogado General remite a la doctrina de Sentencia de 6 de octubre de 1976, asunto De Bloos (14/76) en la que se afirma que los objetivos del Convenio «implican la necesidad de evitar, en la medida de lo posible, la multiplicidad de criterios de competencia judicial en relación con un mismo contrato». Esta misma observación «debe ser igualmente válida si nos hallamos en presencia de un hecho ilícito y no de un contrato»».

${ }^{17}$ En los casos de publicaciones lesivas por el medio virtual, A. L., Calvo Caravaca y J. Carrascosa González, «El Derecho Internacional Privado...», cit., p. 93, señalan que el origen del daño se sitúa en el «lugar donde el responsable toma y ejecuta la decisión de difundir ciertos contenidos en un determinado sitio de Internet».
} 


\section{La regla del mosaico}

43. El siguiente paso en la construcción de un concepto autónomo del foro del «lugar del daño» se da con la Sentencia del Tribunal de Justicia de 7 de marzo de 1995, asunto Shevill (C-68/93), ECLI:EU:C:1995:61, que se refiere, esta vez sí, a un caso de difamación por medio de la prensa.

44. El asunto surge como consecuencia de la publicación en un diario francés, France-Soir, de un artículo relativo a una operación efectuada por la brigada de estupefacientes de la policía francesa en una de las oficinas de cambio explotadas en París por Chequepoint SARL en el que se sugería que formaban parte de una red de tráfico de drogas para la cual había efectuado operaciones de blanqueo de dinero. En el artículo se mencionaba a una de sus trabajadoras, la Sra. Shevill ${ }^{18}$, que parecía también implicada en los hechos delictivos. La Sra. Shevill, Chequepoint SARL, Ixora Trading Inc., y Chequepoint International Ltd ${ }^{19}$ instaron, el 17 de octubre de 1989, ante la High Court of England and Wales, una acción por difamación contra Presse Alliance $S A$ reclamando daños y perjuicios por los ejemplares de France-Soir distribuidos tanto en Francia como en los demás países europeos, incluidos los vendidos en Inglaterra y en el País de Gales, aunque después modificaron sus pretensiones para limitar su reclamación a los perjuicios producidos en Inglaterra y País de Gales ${ }^{20}$.

45. La empresa demandada impugnó la competencia de la High Court of England and Wales para conocer del litigio, alegando que, con arreglo al artículo 5.3 del Convenio de Bruselas, los tribunales franceses eran los competentes para conocer del proceso ya que el «lugar donde se hubiere producido el hecho dañoso» era Francia. Dicha impugnación fue rechazada tanto en primera instancia como en apelación y, finalmente, llegó a la House of Lords que decidió plantear las cuestiones prejudiciales ante el Tribunal de Luxemburgo. El problema fundamental que se somete a la consideración del Tribunal de Justicia consiste en dilucidar qué se entiende por «lugar del daño» a efectos de fijar la competencia internacional en un caso de difamación por medio de la prensa distribuida en varios Estados: ¿será el lugar donde el periódico se imprime y distribuye?, ¿el lugar o lugares donde los particulares leen ese periódico? o ¿el lugar o lugares en los que el demandante goce de buena reputación?

46. El Tribunal toma como premisa las conclusiones de la Sentencia Mines de Potasse que considera plenamente válidas en caso de perjuicios no patrimoniales «como los causados a la fama y a la consideración de una persona física o jurídica por una publicación difamatoria». El Tribunal, igual que sucedió en el asunto Mines de Potasse, estimó que se produce una disociación entre el hecho generador del daño y el lugar donde el daño se manifiesta, pero con la importante diferencia de que en esta ocasión se trata de daños inmateriales y plurilocalizados.

47. La primera conclusión relevante a la que llega el Tribunal es que en este caso de difamación por un artículo de prensa difundido en varios Estados, el lugar del hecho causal «solo puede ser el del lugar del establecimiento del editor de la publicación controvertida, en la medida en que constituye el lugar de origen del hecho dañoso, a partir del cual la difamación se ha manifestado y difundido». Lo importante a efectos de determinar el origen del daño es la acción que causa directamente ese daño y que sirve de fundamento a la pretensión del dañado, sin que tengan relevancia los actos meramente preparatorios, aunque se produzcan dentro de la cadena causal ${ }^{21}$.

\footnotetext{
${ }^{18}$ La señora Shevill tenía su domicilio en Inglaterra, pero había estado tres meses trabajando en París para Chequepoint SARL.

${ }^{19}$ Ixora Trading Inc. explota oficinas de cambio en Inglaterra desde 1974 bajo el nombre de «Chequepoint» y Chequepoint International Ltd es sociedad holding belga con domicilio social en Bruselas, que controla Chequepoint SARL e Ixora Trading Inc.

${ }^{20}$ En el Derecho inglés existe una presunción de perjuicio en materia de difamación, los demandantes no tuvieron que aportar la prueba del perjuicio derivado de la publicación del artículo controvertido.

${ }^{21}$ En este sentido, M. Virgós Soriano y F. J. Garcimartín Alférez, Derecho Procesal Civil Internacional. Litigación Internacional, Civitas, $2^{a}$ edición, 2007, p. 191, que se refieren a la «teoría del último acto».
} 
48. La determinación del acto generador del daño en un caso de difamación por medio de la prensa escrita puede resultar compleja como demuestra la diversidad de respuestas que se han dado por parte de la doctrina, que fundamentalmente oscilan entre la publicación o edición de la noticia o la distribución de la misma, es decir, la puesta a disposición de esa noticia a terceros. De entre las diversas opciones, el Tribunal de Justicia se ha decantado por la publicación o edición como evento causal y considera el lugar del establecimiento del editor como punto de conexión relevante para la atribución de la competencia internacional. Este planteamiento suscita alguna duda porque el lugar de edición o publicación no siempre coincidirá con el establecimiento del editor ${ }^{22}$. Se plantea, por ello, si el Tribunal de Justicia ha pretendido objetivar el establecimiento del editor como el lugar del evento causal en los casos de difamación o si ha optado por el establecimiento del editor en este caso concreto porque es ahí donde se producen todos los actos necesarios para la puesta en circulación de la publicación. Esta última interpretación, que parece la más correcta, no obstaría a que si en otro caso diferente el lugar de publicación fuera distinto del establecimiento del editor, sería ese otro y no el establecimiento del editor el punto de conexión a efectos de determinar la competencia internacional ${ }^{23}$.

49. En todo caso, no se puede ignorar que habitualmente coincidirán el lugar del origen del daño con el lugar donde el demandado tenga su domicilio. Así, en los casos de difamación internacional, el lugar de edición de la publicación difamatoria suele coincidir con el lugar donde la empresa editora tiene su sede social. Por tanto, no estaremos en la mayoría de los casos ante una verdadera alternativa al fuero general del domicilio del demandado.

50. El segundo aspecto importante al que se refiere la sentencia es el lugar de materialización del daño que se concreta en «el lugar donde el hecho causal, que genera la responsabilidad delictual o cuasidelictual de su autor, ha producido sus efectos dañosos en relación con la víctima» y, en un caso de difamación internacional, el ataque al honor y a la reputación de una persona física o jurídica «se manifiesta en los lugares en que la publicación ha sido difundida, cuando la víctima es allí conocida» ${ }^{24}$. Se considera, por tanto, lugar del daño cada uno de los Estados en los que la publicación se ha difundido siempre que el perjudicado sea allí conocido ${ }^{25}$.

51. Tanto el lugar del hecho causal como el lugar de materialización del daño se consideran puntos de conexión suficientes para justificar la competencia internacional del Estado. Hasta aquí la Sentencia Shevill no hace otra cosa que aplicar la doctrina sentada en la Sentencia Mines de Potasse. Sin embargo, el Tribunal no se limita a esto sino que da un paso más y delimita el alcance de la competencia de cada jurisdicción estatal. Los tribunales del Estado del establecimiento del editor, como lugar del hecho causal, tienen competencia para conocer de «la acción de reparación por la integridad del perjuicio causado por el acto ilícito». Los tribunales de cada Estado en el que se haya difundido la publicación difamatoria y donde la víctima alegue haber sufrido un perjuicio «son competentes para conocer de los daños causados en dicho Estado a la reputación de la víctima». Se aparta en este aspecto de la Sentencia

\footnotetext{
${ }^{22}$ A este respecto A., SARAVAlLE, «Forum damni o fora damni», Il Foro Italiano, 1995, IV, págs. 332 a 340, quien firma que el establecimiento del editor puede estar situado en sitio distinto de donde se publica realmente la noticia. Así, por ejemplo, en el caso de ediciones locales de periódicos de difusión internacional, como el Financial Times o Herald Tribune).

${ }^{23}$ En el mismo sentido, J., MASEDA RodríGuez, «Difamación por medio de prensa con daños en varios Estados: el locus delicti commissi a efectos de competencia judicial internacional en el ámbito espacial europeo», Revista General de Legislación y Jurisprudencia, núm. 4/2009, pags. 745 y sigs.; y M., Virgós Soriano y F. J. Garcimartín Alférez, Derecho Procesal Civil..., cit., pág. 193.

${ }^{24}$ El Abogado General, Sr. Marco Darmon, en sus Conclusiones, presentadas el 14 de julio de 1994, analizó la posibilidad de equiparar el lugar del daño con el domicilio de la víctima, como proponía un sector doctrinal (apartados 42 y sigs.). Sin embargo, esta interpretación se rechaza porque «...consagrar dicho fuero equivaldría a conferir la competencia al forum actoris, criterio que, como este Tribunal ha recordado en numerosas ocasiones, no goza del favor del Convenio. Así, en la sentencia Dumez France y Tracoba, este Tribunal cuidó de recordar que el Convenio manifiesta la preferencia del criterio del domicilio del demandado».

${ }_{25}$ Solo son relevantes las víctimas directas y los daños directos, no los indirectos o derivados de los primeros. En este sentido, A. L. Calvo Caravaca y J. Carrascosa González, «El Derecho Internacional Privado...», cit., p. 97 y sigs.
} 
Minas de Potassa que situaba en plano de igualdad el alcance de la competencia del tribunal de origen del daño y del tribunal de materialización del daño, ambos podían conocer de la acción de reparación por la totalidad del perjuicio ocasionado a la víctima. Sin embargo, no debe perderse de vista que en el asunto Minas de Potassa el perjuicio se había ocasionado en un único Estado y en el asunto Shevill nos encontramos ante daños localizados en varios Estados. Esta diferencia no es, desde luego, baladí.

52. El demandante, por tanto, puede acumular todas sus pretensiones resarcitorias ante los órganos jurisdiccionales del Estado donde el demandado tenga su domicilio o donde se encuentre el establecimiento del editor de la publicación ${ }^{26}$ o puede acudir a los tribunales de cada Estado donde la publicación haya sido difundida y la víctima haya sufrido un ataque a su reputación para reclamar únicamente por los perjuicios sufridos en ese Estado.

53. La decisión adoptada por el Tribunal de Luxemburgo coincide con la propuesta por el Abogado General en sus Conclusiones, en las que se barajaron también otras opciones en lo que se refiere al alcance de la competencia del tribunal del lugar del daño. Así, se planteó la solución, propuesta por parte de la doctrina, de reconocer la competencia concurrente del tribunal del lugar del hecho causal y del tribunal del lugar de la producción del daño, de modo que la víctima pudiera demandar por la totalidad del daño sea cual sea el lugar en que éste se haya producido y no solo por el daño acaecido en el territorio nacional del órgano jurisdiccional ${ }^{27}$. Sin embargo, esta interpretación se descarta por dos razones. La primera por el riesgo de forum shopping en la medida en que la víctima se decantará por el foro del lugar en el que pueda obtener una reparación más satisfactoria. La segunda porque si el órgano jurisdiccional del lugar de uno de los daños pudiera conocer de la acción de reparación por daños acaecidos en otros Estados miembros desaparecería el vínculo de proximidad entre el foro y el litigio que es el fundamento último de esta competencia especial ${ }^{28}$.

54. No se considera tampoco asumible la propuesta de centralizar en el tribunal del lugar donde se haya producido el «daño principal» la competencia para decidir sobre la totalidad de los daños producidos en cualquiera de los Estados miembros. Esta interpretación se fundamenta en la extensión de la doctrina sentada por la Sentencia de 15 de enero de 1987, asunto Shenavai (C-266/85), ECLI:EU:C:1987:11, que en un litigio referido a varias obligaciones derivadas de un mismo contrato estimó que la competencia se ha de determinar de acuerdo con el principio según el cual lo accesorio sigue a lo principal y, por tanto, será la obligación principal la que sirva como punto de conexión para fijar la competencia. El Abogado General rechaza esta opción porque supondría «vincular la competencia del Juez a la apreciación del fondo del litigio» y no resultará en muchos casos sencillo determinar dónde se ha producido ese «daño principal» $»^{29}$. No se trata de un criterio claro y con un grado suficiente de objetividad que permita una aplicación uniforme en todos los Estados de la Unión Europea.

55. En definitiva, la aportación fundamental de la Sentencia Shevill está en reconocer una extensión diferente a la competencia del tribunal en función de que se trate del órgano jurisdiccional del lugar del hecho causal o del órgano jurisdiccional del lugar de producción del daño. Esta doctrina, conocida como «regla del mosaico» ${ }^{30}$, tiene como inevitable consecuencia la «atomización» de la competencia

\footnotetext{
${ }^{26}$ El establecimiento del editor y el domicilio del demandado (que será, normalmente, el propio editor) serán en muchos casos coincidentes. Así lo reconoce la propia Sentencia Shevill (apartado 26). No obstante, algunos autores se muestran favorables a incluir dentro de ese concepto de «establecimiento del editor» a los establecimientos secundarios con el fin de dar una opción más al demandante para la protección de sus intereses. En este sentido, J., SÁnchez SANTIAGo y J.J., IzQUierdo Peris, «Difamar en Europa: las implicaciones del asunto Shevill», en Revista de Instituciones Europeas, vol. 23, núm. 1/1996, p. 152.

${ }^{27}$ Cfr., apartados 30 a 32 de las Conclusiones, en las que se recoge esta interpretación propuesta por parte de la doctrina alemana.

${ }^{28} \mathrm{Cfr}$., apartados 65 y sigs. de las Conclusiones.

${ }^{29} \mathrm{Cfr}$., apartados 80 y sigs. de las Conclusiones.

${ }^{30}$ Un extenso análisis sobre la teoría del mosaico y sus implicaciones puede verse en A. L. CAlvo CARAvaca y J. CARRASCOSA GonZÁLEZ, «El Derecho Internacional Privado...», cit., pp. 96 y sigs.
} 
y así lo reconoce la propia Sentencia cuando afirma que «la apreciación de los distintos aspectos de un mismo litigio por distintos órganos jurisdiccionales presenta inconvenientes».

56. Estos inconvenientes son mucho más evidentes si la difamación no se produce a través de un artículo de prensa, como en esta ocasión, sino por el medio virtual con un alcance potencialmente universal. La multiplicación de los foros de competencia podría conducir a una sucesión de procesos en cada uno de los Estados en los que el contenido difamatorio es accesible a través de internet y con el inconveniente añadido de la falta de armonización de las normas de conflicto y del derecho sustantivo aplicable para resolver sobre el fondo. Esta situación se aleja mucho de los fines de la buena administración de justicia y de la previsibilidad de los criterios de atribución de competencia a la que aspira la normativa europea.

\section{Un nuevo fuero de competencia internacional: el centro de intereses de la persona física}

57. Un hito importante en la delimitación del fuero del lugar del daño en los litigios por vulneración de los derechos de la personalidad lo representa la Sentencia del Tribunal de Justicia de 25 de octubre de 2011, asuntos acumulados eDate Advertising/Olivier Martínez (C-509/09 y C-161/10), ECLI:EU:C:2011:685. Es la primera ocasión en la que el Tribunal de Luxemburgo se mete de lleno en la problemática que representa la delimitación de la competencia internacional en los casos de lesión del derecho al honor o a la intimidad por la información publicada a través de internet ${ }^{31}$.

58. El primero de los asuntos de los que trae causa esta Sentencia se refiere a la publicación en un portal de Internet, gestionado por la sociedad eDate Advertising, radicada en Austria, de información sobre los recursos interpuestos por dos personas que habían sido condenadas por un órgano jurisdiccional alemán a cadena perpetua por el asesinato de un conocido actor. Uno de los aludidos presentó demanda ante los órganos jurisdiccionales alemanes para que instaran a dicha empresa a dejar de vincular su nombre completo con el crimen cometido. Se ejercita, por tanto, una acción de cesación. En este contexto, eDate Advertising niega la competencia internacional de los órganos jurisdiccionales alemanes para pronunciarse sobre ese litigio puesto que considera que solo puede ser demandada ante los tribunales austriacos.

59. El segundo de los asuntos hace referencia a un texto redactado en lengua inglesa y publicado en el sitio de Internet del periódico británico Sunday Mirror en el que se daban detalles sobre un encuentro entre una cantante australiana y un actor francés. Este último y su padre entablaron en Francia una acción judicial contra la sociedad británica MGN, editora del Sunday Mirror, para lograr la reparación de los daños causados por la intromisión en su vida privada. La sociedad demandada niega la competencia internacional del tribunal francés ya que estima que no hay una vinculación suficiente entre la publicación en Internet en el Reino Unido y el daño alegado en territorio francés.

60. El Tribunal Federal de Justicia de Alemania y el Tribunal de Grande Instance de Paris, plantearon al Tribunal de Justicia sendas cuestiones prejudiciales para preguntar en esencia cómo debía interpretarse el fuero del lugar del daño en caso de lesiones de los derechos de la personalidad a través de los contenidos publicados en un sitio de Internet y si se ha de aplicar o no en este contexto la doctrina de la Sentencia Shevill.

\footnotetext{
${ }^{31}$ Sobre los problemas derivados de internet y la protección de la privacidad, cfr., entre otros, A.L. CALVo CARAVACA y J. Carrascosa González, Conflictos de leyes y conflictos de jurisdicción en internet, Madrid, Colex, 2001 y, entre la doctrina extrnajera, O. FERACI, «Diffamazione internazionale a mezzo di Internet: quale foro competente? Alcune considerazioni sulla sentenza 'eDate'», Rivista di Diritto Internazionale, 2012, pp. 461-469 ó G. ZARRA, «Conflitti di giurisdizione e bilanciamento dei diritti nei casi di diffamazione internazionale a mezzo internet», Rivista di Diritto Internazionale, 2015, pp. 1234-1262.
} 


\section{A) La adaptación de la jurisprudencia al contexto de internet}

61. El Tribunal de Justicia comienza reconociendo las evidentes diferencias entre la publicación de contenidos en internet y su difusión a través de un medio de comunicación impreso. En la red desaparece la fragmentación territorial de la información porque el «ciberespacio» carece de fronteras y límites y permite globalizar la comunicación. También se difumina la dimensión temporal de la información porque los contenidos permanecen, en principio, indefinidamente en internet y pueden ser consultados por un número indefinido de usuarios en todo el mundo, con independencia de la intención del emisor de la noticia.

62. Estas particularidades tienen como consecuencia que con internet se «reduce la utilidad del criterio relativo a la difusión» porque su alcance es, en principio, universal y «no siempre es posible, desde el punto de vista técnico, cuantificar esa difusión con certeza y fiabilidad en relación con un Estado miembro emisor particular ni, por lo tanto, evaluar el daño exclusivamente causado en ese Estado miembro». Con estos términos parece (pero solo parece) que el Tribunal de Justicia está descartando que la mera accesibilidad a los contenidos difamatorios o lesivos del derecho a la intimidad constituya un punto de conexión suficiente para justificar la competencia internacional de un Estado. Sin embargo, como después se verá, no es ésta la conclusión que se puede extraer de la Sentencia sino justamente la contraria.

63. En todo caso, el Tribunal de Justicia reconoce las dificultades de aplicar el criterio del lugar del daño, consagrado en la Sentencia Shevill, en el contexto de internet y, por ello, estima que es necesaria una adaptación que permita a la víctima de una lesión de un derecho de la personalidad a través de internet acudir «en función del lugar en el que se haya producido el daño causado en la Unión Europea por dicha lesión, a un fuero por la totalidad de ese daño». Esa adaptación se alcanza mediante un nuevo concepto: el «centro de intereses de la víctima». Ese nuevo criterio de atribución de competencia internacional se justifica en atención a la gravedad de la lesión y la posibilidad de acceder desde cualquier lugar a la información dañina. Características que son específicas de internet como medio de difusión de contenidos.

64. El centro de intereses constituye un criterio de conexión adicional a los admitidos hasta el momento por la jurisprudencia y permite a la víctima ejercitar acciones de cesación o acciones por la totalidad de los daños derivados de la difusión de información lesiva en cualquier Estado. Se trata, sin duda, de una aportación fundamental porque con la Sentencia Shevill solo se podían ejercitar acciones de reparación por la totalidad de los daños ante los tribunales del Estado del domicilio del demandado, como fuero general, o del establecimiento del editor, como lugar de origen del daño. Y tanto uno como otro solían coincidir con cierta frecuencia.

65. El Tribunal de Justicia estima que son dos la ventajas que se derivan de la adaptación de su jurisprudencia previa para atribuir competencia respecto al conjunto del daño a los tribunales del centro de intereses de la víctima. La primera es que este nuevo criterio de atribución de competencia se corresponde con el objetivo de la buena administración de justicia y la sustanciación adecuada del proceso. La segunda es que este foro es conforme con el objetivo de la previsibilidad de las normas de competencia, pues «permite, al mismo tiempo, al demandante determinar fácilmente el órgano jurisdiccional ante el cual puede ejercitar una acción y al demandado prever razonablemente ante qué órgano jurisdiccional puede ser demandado».

66. No cabe duda de que la interpretación del TJUE en la Sentencia eDate Advertising/Olivier Martínez favorece la posición de las víctimas de vulneraciones de derechos de la personalidad a través de internet en la medida en que sienta las bases para que se puede ejercitar cualquier acción de alcance general, como una acción de cesación o una acción de indemnización por la totalidad de los daños, en un fuero distinto al del domicilio del demandado o el establecimiento del editor. Eso sí, el TJUE deja claro que este fuero más amplio es compatible con la posibilidad de ejercitar una acción ante los tribunales de cada Estado miembro «en cuyo territorio el contenido publicado en internet sea, o haya sido, accesible», los cuales serán competentes únicamente para conocer del daño causado en ese Estado. En 
la Sentencia eDate Advertising/Olivier Martínez no se hace referencia ni siquiera a la necesidad de que la víctima sea conocida en el Estado en cuyo territorio la información es accesible, pero parece claro que esta exigencia, introducida por la Sentencia Shevill, sigue estando vigente porque si la persona es desconocida en ese Estado no sufrirá de ordinario ningún perjuicio en ese territorio y, en consecuencia, no podrá reclamar allí su reparación. No se puede, por ejemplo, destruir la reputación de una persona en un Estado donde no tiene reputación ninguna, ni buena ni mala, porque no es conocida.

67. No deja de ser cuanto menos llamativo que la mera accesibilidad del contenido publicado en internet se mantenga como punto de conexión suficiente para justificar la competencia judicial internacional. No debe olvidarse que el propio TJUE ha reconocido la imposibilidad práctica de cuantificar con certeza y fiabilidad el alcance de la difusión en un Estado concreto y el valor económico del daño causado en exclusiva en ese Estado. La conservación de este criterio de competencia en las acciones derivadas de la vulneración de un derecho de la personalidad por medio del «ciberespacio» no parece compatible con la buena administración de justicia ni mucho menos con la previsibilidad de las normas de competencia. Todos los Estados de la Unión Europea tendrán, en principio, competencia internacional, aunque sea limitada, para conocer de las demandas por vulneración de un derecho de la personalidad a través de internet por el simple hecho de que el contenido lesivo sea accesible desde ese Estado y la persona sea allí conocida. Es cierto que la víctima puede verse disuadida de llevar a cabo este peregrinaje por cada una de las jurisdicciones estatales, máxime cuando no hay criterios claros que permitan la cuantificación de los daños en cada Estado, y en la mayoría de los casos preferirá acudir a una sola jurisdicción estatal para reclamar por la totalidad de los daños. Sin embargo, no deja de ser criticable que el TJUE deje la puerta abierta a ese peregrinaje jurisdiccional ${ }^{32}$.

\section{B) La determinación del lugar del centro de intereses de la víctima}

68. Un aspecto clave para la aplicación práctica de la doctrina de la Sentencia eDate Advertising/ Olivier Martínez es la delimitación del lugar que constituye el centro de intereses de la víctima a efectos de determinar la competencia internacional. El TJUE, sin embargo, se limita a afirmar que «por lo general, el lugar en el que una persona tiene su centro de intereses corresponde a su residencia habitual. Sin embargo, una persona puede tener su centro de intereses también en un Estado miembro en el que no resida habitualmente, en la medida en que otros indicios, como el ejercicio de una actividad profesional, permitan establecer la existencia de un vínculo particularmente estrecho con ese Estado miembro».

69. El Tribunal de Luxemburgo no ofrece elementos interpretativos adicionales que permitan concretar con un mínimo de precisión los requisitos necesarios para calificar a un determinado lugar como el centro de intereses de la víctima. Incluso parece que una misma persona puede tener varios centros de intereses, al menos dos: el lugar donde la persona tenga su residencia habitual y el lugar donde desarrolle su actividad profesional, si cada uno se encuentra en Estados diferentes. Y ello sin descartar que pueda haber otro centro de intereses de esa persona si tiene algún «vínculo particularmente estrecho» con otro Estado miembro ${ }^{33}$. Es evidente, pues, la vaguedad de este nuevo concepto y las dificultades que puede conllevar su aplicación por los tribunales nacionales.

\footnotetext{
${ }^{32}$ A este respecto E. Torralba Mendiola, «La difamación en la era de las comunicaciones...», cit., pág. 16, manifiesta lo siguiente: «...si se entiende que la excesiva multiplicidad de foros a los que la aplicación del criterio sentado en Shevill conduce cuando se ha actuado a través de Internet es inadecuado y que es necesario admitir un nuevo criterio que permita reclamar por la totalidad de los daños que resulte cercano a la víctima y que además sea previsible para el emisor, establezcamos ese criterio, pero eliminemos los que no respetan esos requisitos. Eliminemos la posibilidad de reclamar en cualquier lugar por los daños sufridos en él». En contra de que la mera accesibilidad del contenido sea suficiente para atribuir competencia judicial a un determinado Estado se manifiesta también C. I., Cordero Álvarez, Litigios internacionales ..., cit., pp. 151 y sigs,

${ }^{33}$ En este sentido, I. Lorente Martínez, «Lugar del hecho dañoso y obligaciones extracontractuales. La Sentencia del TJUE de 25 de octubre de 2011 y el coste de la litigación internacional en internet», en Cuadernos de Derecho Transnacional, Marzo/2012, vol. 4, n 1, p. 294, afirma: «La posibilidad de que el lugar del «centro de intereses del presunto perjudicado» se
} 
70. El TJUE no ha considerado oportuno en la Sentencia eDate Advertising/Olivier Martínez exigir algún tipo de conexión específica entre el contenido de la información lesiva del derecho al honor, a la intimidad o a la propia imagen y el lugar que constituye el centro de intereses de la víctima como condición para justificar la competencia por la totalidad de los daños ocasionados en cualquier Estado.

71. Sobre esta cuestión es mucho más explícita la propuesta del Abogado General, Sr. Cruz Villalón, en sus Conclusiones presentadas el 29 de marzo de 2011. El Abogado General proponía completar los criterios de la Sentencia Shevill con un nuevo foro que permita decidir sobre la totalidad de los daños a aquella jurisdicción que esté mejor situada para analizar todos los intereses en juego. Ese foro se concreta en el lugar del «centro de gravedad del conflicto» que se identifica con la conjunción de dos elementos. El primero se refiere al titular del derecho de la personalidad y se ubica donde aquél tenga su «centro de intereses», entendiendo por tal el lugar donde el sujeto desarrolla esencialmente su proyecto vital. No es suficiente, por tanto, con que la víctima sea simplemente conocida. El segundo de los elementos se refiere a la naturaleza de la información. Ésta ha de ser objetivamente relevante en ese espacio territorial o, con otros términos, «la información que suscita el litigio debe expresarse en unos términos que, a la vista de las circunstancias que rodean la noticia, constituyan una información que suscite interés en un territorio y, en consecuencia, incite activamente a los lectores en dicho territorio a acceder a ella» ${ }^{34}$.

72. El Tribunal de Luxemburgo solo ha reflejado en la Sentencia eDate Advertising/Olivier Martínez una parte de la propuesta del Abogado General: la referida al «centro de intereses» de la víctima. No ha exigido, sin embargo, que la información lesiva tenga algún tipo de relevancia en el territorio donde la víctima tiene su centro de intereses y la delimitación de ese lugar se lleva cabo con una fórmula demasiado imprecisa como es la existencia de un «vínculo particularmente estrecho» de la víctima con el territorio del Estado, sin hacer mención alguna al desarrollo del proyecto vital de la víctima. No se puede descartar, por ello, que la información presuntamente lesiva carezca de relevancia en ese centro de intereses de la víctima y que, pese a no haber causado perjuicios en ese territorio, sean competentes los tribunales del mismo para conocer de todos los perjuicios causados en otros Estados con base exclusivamente en el vínculo estrecho entre la persona y el territorio ${ }^{35}$.

73. La atribución de competencia internacional a los tribunales del centro de intereses de la víctima con independencia de que la información fuera claramente dirigida a otro Estado en el que ese

concrete con arreglo a otros criterios distintos, como por ejemplo, el lugar donde el sujeto transcurre sus vacaciones de forma pública, no resulta descartable. En efecto, el TJUE solo ha introducido una excepción a la regla general «residencia habitual» de la persona presuntamente perjudicada. En concreto, se trata del lugar donde la persona desarrolla su actividad profesional. Pero no ha afirmado que sea «la única excepción posible». De ese modo, puede darse el caso de que una persona tenga su centro de intereses en un Estado miembro en el que ni tenga su residencia habitual ni desarrolle su actividad profesional: lugar donde la persona transcurre públicos períodos prolongados de descanso, lugar donde está hospitalizada la persona, lugar donde desarrolla actividades filantrópicas, etc».

${ }^{34}$ Vid. Apartado 60 de las Conclusiones.

${ }^{35}$ Sobre este particular, I. LoRENTE MARTíNEZ, «Lugar del hecho dañoso...», cit., p. 294 estima que «parece también adecuado que la determinación del «centro de intereses» se realice mediante una ponderación del tipo y carácter del litigio en cuestión. Así, una información presuntamente difamatoria en «materia familiar» no es igual a una información presuntamente difamatoria en «materia profesional». Por ello, un sujeto podría tener varios «centros de intereses» según el objeto de la información presuntamente ilícita». Sin embargo, esta autora concluye en la pág. 298, que «la Sentencia dictada por el TJUE no exige, en particular, que la información revista un «especial interés noticiable» en el país donde radica el centro de intereses del demandante / presunta víctima. El foro del centro de intereses de la presunta víctima en un Estado miembro, es, por tanto, un «foro procesal puro» de competencia judicial internacional. Un foro que no exige la presencia de elementos extraídos del fondo del asunto, que no requiere que la información vertida en Internet revista unos caracteres determinados, ni exige que la información «incite a los lectores de un concreto país a acceder a tal información» ni que los contenidos difundidos en Internet posean un «interés informativo» o presenten un concreto «impacto informativo» en un determinado país».

Efectivamente, esta vinculación entre la información y el lugar donde la víctima tiene su centro de intereses puede ser conveniente, pero, desde luego, la Sentencia no solo no la exige sino que omite toda referencia a esta cuestión, que sí había planteado el Abogado General. 
contenido pudiera tener interés o relevancia suscita la duda de si está justificado aplicar este nuevo fuero exclusivamente a los casos en que la lesión del derecho al honor, a la intimidad o a la propia imagen se materializa por el medio virtual. Si la información lesiva se ha manifestado a través de un medio impreso o de radio o televisión en varios Estados, no se ve razón alguna que impida atribuir a los tribunales del centro de intereses de la víctima competencia para decidir sobre la totalidad de los daños y, en paralelo, justifique sí reconocer esa competencia cuando la difusión se ha realizado por internet ${ }^{36}$. No parece que las particularidades de internet sean por sí solas suficientes para justificar la exclusión de esta nueva regla competencial en otros ámbitos.

\section{La extensión del nuevo foro a las personas jurídicas: el centro de intereses de las personas ju- rídicas}

74. El camino iniciado por el TJUE en la creación de nuevos foros de competencia internacional continua en la STJUE de 17 de octubre de 2017, asunto Bolagsupplysningen (C-194/16), ECLI:EU:C:2017:766.

75. En esta ocasión, una sociedad estonia que desarrolla actividades en Suecia fue incluida en la lista negra del sitio web de una federación de empresarios sueca por cometer supuestamente actos de fraude y engaño. En el foro de discusión se incluyeron comentarios con llamamientos directos al uso de la violencia contra Bolagsupplysningen y sus empleados. La sociedad estonia demandó a la federación sueca ante los tribunales estonios solicitando que condenasen a la demandada a rectificar la información y suprimir los comentarios. Con carácter subsidiario, la demandante también solicitó una indemnización por los daños y perjuicios sufridos como consecuencia del ataque a su honor y reputación.

76. El Tribunal Supremo de Estonia alberga dudas sobre la competencia de los tribunales estonios para conocer de este asunto y plantea al Tribunal de Justicia tres cuestiones prejudiciales ${ }^{37}$. La primera, si los órganos jurisdiccionales estonios pueden conocer de esta acción con base en el fuero del centro de intereses. En caso afirmativo, plantea cómo se determina el centro de intereses de una persona

${ }^{36}$ P. De Miguel Alonso, «Competencia judicial y protección de los derechos de la personalidad en internet», Diario La Ley, 31 de enero de 2012, págs. 1 a 3, considera lo siguiente: «Ahora bien, la atribución de competencia a los Tribunales del centro de intereses de la víctima para conocer de la responsabilidad por la totalidad del daño (en todo el mundo) derivado de la difusión en Internet de la información lesiva por el supuesto responsable con independencia de que tal difusión tuviera lugar en circunstancias en las que aparecía claramente dirigida solo a otro concreto país, por ejemplo, el del establecimiento del supuesto responsable en cuyo idioma local se publicó la información en su sitio web, solo disponible en ese idioma — distinto del inglés, español u otro de uso internacional, así como del hablado en el lugar del centro de intereses de la víctima-, puede suscitar reflexiones adicionales. Así, sobre todo al hilo de las situaciones en las que la información se difunde por Internet pero a través de un medio restringido en virtud de controles - típicamente basados en la geolocalización - a usuarios de un Estado diferente al del centro de intereses de la víctima, cabe plantearse si existe justificación para un tratamiento diferenciado con carácter general entre la difusión de información a través de Internet y por otros medios (cuál es el centro de intereses de la víctima en el que la información será típicamente noticiable es también previsible para quien difunde la información solo en un medio impreso). Además, el que la publicación de la información por el supuesto responsable tenga lugar únicamente en un medio impreso en realidad no impide que especialmente en el actual contexto de la sociedad de la información esos contenidos puedan tener impacto en otros países (como el del centro de intereses de la víctima), en particular en la medida en que otros medios (digitales) recojan la información difundida por el medio impreso_. En esos casos, de hecho, las circunstancias que concurren pueden ser en la práctica semejantes a las que están presentes en aquellas situaciones en las que la información de difunde a través de Internet, pero con controles que limitan el acceso a la información a las personas que se encuentren en determinados territorios». En sentido contrario, sí considera que las particularidades de internet justifican un tratamiento diferenciado L., GILLIES, «Jurisdiction for cross-border breach of personality and defamation», The International and Comparative Law Quarterly, october 2012, Vol. 61, No. 4, pp. 1007-1016

${ }^{37}$ En el litigio principal, la demanda se interpuso no solo por la sociedad estonia Bolagsupplysningen sino también por una empleada de la misma, quien solicitaba una indemnización por daño moral. Sin embargo, la cuestión prejudicial solo se refiere a la competencia de los tribunales estonios para decidir en relación con la persona jurídica. La razón de esta distinción puede encontrase en que, de acuerdo con la Sentencia eDate Advertising/Olivier Martínez, el centro de intereses de la persona física se puede situar en Estonia, donde tiene su residencia habitual. 
jurídica. Por último, si la competencia de los tribunales estonios se limita a decidir sobre los daños y perjuicios causados en su territorio, se plantea si pueden también ordenar a la federación sueca que rectifique y suprima la información lesiva.

77. En este caso concurren dos elementos novedosos con respecto a la Sentencia eDate Advertising/Olivier Martínez que requieren un replanteamiento de la anterior doctrina del Tribunal de Justicia. La primera novedad está en que es una persona jurídica, y no una persona física, la que considera lesionados sus derechos. La segunda, no menos relevante, es que la acción ejercitada a título principal no es indemnizatoria sino una acción de rectificación. Respecto de este tipo de acción el Tribunal de Justicia había pasado de puntillas en el asunto eDate Advertising/Olivier Martínez, pero ahora el tribunal remitente le solicita un pronunciamiento expreso sobre el particular.

78. El Tribunal de Justicia en la Sentencia Bolagsupplysningen estima que las personas jurídicas también pueden beneficiarse de la posibilidad de ejercitar acciones por la totalidad del daño en el lugar donde se encuentre su centro de intereses. Esta conclusión se fundamenta en que no se trata de un fuero establecido para proteger al demandante o a la parte más débil, como sucede, por ejemplo, en materia de contratos celebrados con consumidores. Se trata de una regla de competencia en aras a la recta administración de justicia por la estrecha conexión existente entre el litigio y el órgano jurisdiccional que ha de resolverlo. No existe, por tanto, razón alguna para distinguir entre persona física y persona jurídica a estos efectos ${ }^{38}$.

79. Con esta premisa, tienen un indudable interés las consideración del Tribunal de Justicia acerca de cómo se localiza el centro de intereses de una persona jurídica a efectos de fijar la competencia internacional. Ya se vio que las personas físicas tienen su centro de intereses normalmente en su residencia habitual, aunque éste puede estar también en otro lugar con el que la persona tenga un «vínculo particularmente estrecho». Esto puede inducir a pensar que el centro de intereses de las personas jurídicas estará de ordinario donde se encuentre su domicilio social. Sin embargo, el Tribunal de Justicia no se decanta por esta interpretación. El criterio básico para determinar dónde se encuentra el centro de intereses de una persona jurídica que, como en el caso, desarrolla una actividad económica, corresponde al lugar donde su reputación comercial es mayor y, por tanto, se determina en función del lugar en el que ejerce la parte esencial de su actividad económica. En atención a lo anterior, el centro de intereses de una persona jurídica puede coincidir o no con su domicilio social ${ }^{39}$.

${ }^{38}$ El Tribunal de Luxemburgo no entra a valorar si las personas jurídicas son o no titulares de derechos de la personalidad y en qué medida pueden ser estos derechos lesionados. Se trata de una cuestión que habrá de decidirse conforme a la legislación sustantiva aplicable. En este sentido, P. A. De Miguel Asensio, «Reputación de las sociedades: tutela frente a la difusión de información lesiva a través de internet», en La Ley Unión Europea, núm. 53, 30 de noviembre de 2017, págs. 4 y 5, afirma que la caracterización a efectos del artículo 7.2 del RBIbis de ciertos bienes como derechos de la personalidad en relación con las personas jurídicas, en especial las dedicadas a actividades económicas, puede plantear cuestiones complejas y condicionar el alcance de esta regla de competencia.

${ }^{39}$ En concreto, la Sentencia afirma, en los apartados 41 y 42, lo siguiente: «Aunque el centro de intereses de una persona jurídica puede coincidir con el lugar de su domicilio cuando ejerce la totalidad de sus actividades o una parte esencial de éstas en el Estado miembro en que está situado dicho domicilio y, en consecuencia, la reputación de que goza allí es más importante que en cualquier otro Estado miembro, la ubicación del domicilio no constituye en sí misma un criterio decisivo en el marco de tal análisis.

De este modo, cuando, como sucede en el litigio principal, la persona jurídica de que se trata desarrolla la mayor parte de sus actividades en un Estado miembro distinto del de su domicilio, cabe presumir que la reputación comercial de esta persona jurídica que puede verse afectada por la publicación controvertida es más importante en ese Estado miembro que en cualquier otro y que, en consecuencia, una eventual lesión de esta reputación se experimentará con mayor intensidad en él. En esta medida, los tribunales de dicho Estado miembro son los mejor situados para examinar la existencia y el posible alcance de esa supuesta lesión, máxime cuando en el caso de autos su origen está en la publicación de información y comentarios supuestamente inexactos o difamatorios en un sitio de Internet destinado a profesionales, administrado en el Estado miembro en el que la persona jurídica afectada ejerce la mayoría de sus actividades, información y comentarios que, teniendo en cuenta la lengua en la que han sido redactados, están destinados esencialmente a ser comprendidos por las personas que residen en dicho Estado miembro». 
80. El Tribunal de Justica admite también la posibilidad de que no se pueda determinar el centro de intereses de la persona jurídica porque no haya elementos para afirmar que la actividad económica de la persona jurídica sea preponderante en un determinado Estado. En esas circunstancias, la persona jurídica no podrá demandar para obtener una indemnización íntegra del perjuicio sufrido sobre la base del lugar del daño del artículo 7.2 del RBIbis. Se excluirá, por tanto, la aplicación de este criterio de competencia.

81. El Tribunal de Justicia no ha acogido la propuesta del Abogado General que proponía acabar con la regla del mosaico en los procesos por vulneración de derechos de la personalidad por medio de internet. La alternativa más restrictiva sugerida en las Conclusiones del Abogado General consistía en limitar los fueros de competencia internacional a dos, el del domicilio del demandado y el del centro de intereses de la víctima, ambos con alcance para decidir sobre la totalidad de los perjuicios ocasionados. Se pretende con ello evitar la extensión de la doctrina sentada por la Sentencia Shevill al ámbito de internet porque implica reconocer simultáneamente la competencia de un gran número de jurisdicciones: todas aquellas desde las que sea accesible el contenido presuntamente difamatorio publicado en la red, aunque sea para decidir sobre un aspecto concreto como es el de los perjuicios ocasionados en el territorio de ese concreto Estado ${ }^{40}$. No se detiene el Tribunal de Luxemburgo a valorar la conveniencia de revisar la aplicación de su anterior jurisprudencia al marco de internet sino que, sin entrar en justificación alguna, se limita a confirmar, como ya advirtió en la Sentencia eDate Advertising/Olivier Martínez, que la persona que se considera lesionada puede ejercitar una acción «ante los tribunales de cada Estado miembro en cuyo territorio el contenido publicado en internet sea o haya sido accesible, los cuales son competentes únicamente para conocer del daño causado en el territorio del respectivo Estado miembro».

\section{La competencia del tribunal del lugar del daño para decidir sobre acciones de rectificación o supresión de la información presuntamente lesiva}

82. En íntima relación con la competencia limitada de ciertos tribunales estatales, se plantea una cuestión relevante que hasta el momento no había tenido una respuesta por parte del Tribunal de Justicia. Se trata de determinar si los tribunales de cada Estado en cuyo territorio la información publicada en internet sea o haya sido accesible pueden decidir sobre la rectificación de esa información o su supresión, además de sobre la indemnización de los daños ocasionados en ese territorio.

83. El Tribunal de Luxemburgo da una respuesta en la Sentencia Bolagsupplysningen, en cuya virtud «habida cuenta de la naturaleza ubicua de los datos y los contenidos puestos en línea en un sitio de internet y de que el alcance de su difusión es, en principio, universal (...), una demanda que tenga por objeto la rectificación de los primeros y la supresión de los segundos es única e indivisible y, en consecuencia, solo puede interponerse ante un tribunal competente para conocer íntegramente de una acción de indemnización del daño, (...), y no ante un tribunal que carezca de esa competencia». En consecuencia, la limitación de la competencia de los tribunales del lugar del daño impide a éstos decidir sobre acciones de rectificación o cesación con alcance ilimitado. Solo los tribunales del domicilio del demandado, del lugar de origen del daño o del centro de intereses de la persona física o jurídica tendrán competencia para pronunciarse sobre este tipo de acciones de alcance genera ${ }^{41}$.

\footnotetext{
${ }^{40}$ Cfr. Conclusiones del Abogado General, Sr. Michal Bobek, presentadas el 13 de julio de 2017, apartados 73 y siguientes.

${ }^{41}$ El Abogado General, Sr. Michal Bobek, en las Conclusiones presentadas el 13 de julio de 2017, apartados 119 y sigs., consideraba que no hay base legal para establecer esa limitación competencial y, por tanto, si un órgano jurisdiccional de un Estado miembro es competente para conocer de una acción de indemnización por daños y perjuicios en materia extracontractual, debe poder pronunciarse sobre todas las medida de reparación previstas en su Derecho interno. A favor de esta interpretación se manifiesta también A. Merchán Murillo, «El centro de intereses de la persona jurídica: comentario a la Sentencia del TJUE de 17 de octubre de 2017, Bolagsupplysningen OÜ, Ingrid Ilsjan y Svensk Handel AB, C-194/16», Cuadernos de Derecho Transnacional, Octubre/2018, vol. 10, № 2, p. 894.
} 
84. El Tribunal de Justicia no va más allá y no entra a valorar si esos órganos jurisdiccionales con competencia limitada pueden decidir también con alcance limitado sobre cuestiones distintas de la indemnización de los daños y perjuicios ocasionados en ese concreto territorio estatal. Así, a modo de ejemplo, se puede plantear el bloqueo o la limitación del acceso a la información presuntamente dañina para la víctima, pero no con alcance universal sino limitado al Estado en cuyo territorio se encuentran los tribunales que deciden sobre esa demanda.

85. La respuesta a esta cuestión debe ser, a mi juicio, afirmativa, al menos por dos razones. La primera, porque la adopción de este tipo de medidas de ámbito limitado es perfectamente compatible con la limitación de la competencia de los tribunales del lugar del daño. Y esa limitación es la única razón en la que el TJUE ha basado la negativa a que estos tribunales conozcan de acciones de rectificación o supresión de la información ${ }^{42}$. La segunda, porque si el tribunal que decide sobre la indemnización de los perjuicios en un determinado Estado no tiene potestad para vedar el acceso a la información en ese Estado, se seguirán ocasionando nuevos perjuicios susceptibles de indemnización hasta que la persona decida acudir a alguno de los fueros sin limitaciones por razón del territorio. Parece, pues, más razonable que el propio tribunal que decida sobre la indemnización de los daños, pueda, si así se ha solicitado, evitar que se puedan ocasionar nuevos daños en el futuro en el mismo territorio.

\section{La Resolución del Instituto de Derecho Internacional sobre internet y la vulneración de la pri- vacidad: ¿un posible modelo para el legislador de la Unión Europea?}

86. El Instituto de Derecho Internacional (en adelante, IDI) ha elaborado la Resolución de 31 de agosto de 2019 sobre la competencia judicial internacional, la ley aplicable y el reconocimiento y ejecución de resoluciones en materia de vulneración de los derechos de la personalidad a través de internet ${ }^{43}$. En esta Resolución, el IDI hace una propuesta para unificar los criterios en las cuestiones más problemáticas que suscita la lesión del derecho al honor, a la intimidad o a la propia imagen por medio de internet. Se trata, sin duda, de una difícil tarea a la vista de la imposibilidad hasta el momento de adoptar un acuerdo que permita contar con normas comunes sobre la ley aplicable ni siquiera en el ámbito más restringido de la Unión Europea, así como de las dudas interpretativas que suscita la aplicación del fuero en materia de responsabilidad extracontractual previsto en el Reglamento Bruselas I bis.

87. La propuesta del IDI no ofrece una solución global para todos los casos de vulneración de los derechos de la personalidad con carácter transfronterizo sino solo para aquellos en los que el medio empleado para difundir la información presuntamente dañina es internet. Quedan fuera, por tanto, las lesiones transfronterizas de los derechos de la personalidad en las que el contenido difamatorio se ha puesto en circulación por otras vías. No puede negarse que la utilización de internet confiere a la información difundida un alcance típicamente transfronterizo y precisamente por esa razón es en esos casos en los que se suelen suscitar los problemas más complejos. Sin embargo, no parece que esto sea motivo suficiente para excluir de una eventual propuesta de solución otras situaciones que a día de hoy no cuentan con un adecuado tratamiento.

\footnotetext{
${ }^{42}$ En el mismo sentido, cfr., P. A. De Miguel Asensio, «Reputación de las sociedades...», cit., p. 7.

${ }^{43}$ «Internet and the Infringement of Privacy: Issues of Jurisdiction, Applicable Law and Enforcement of Foreign Judgments (Injuries to Rights of Personality through the Use of the Internet: Jurisdiction, Applicable Law and Recognition of Foreign Judgments)», accesible en http://www.idi-iil.org/app/uploads/2019/09/8-RES-EN.pdf. Sobre la misma Resolución hay un Informe

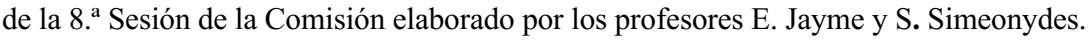




\section{El principio holístico, los criterios de fijación de la competencia internacional y el reconocimien- to y ejecución de resoluciones extranjeras.}

88. El Capítulo I de la Resolución, dedicado a los conceptos y principios generales, proclama el llamado «principio holístico» como criterio básico para la determinación de la competencia internacional. Conforme al artículo 3, la persona que ha sufrido o puede sufrir una vulneración de sus derechos de la personalidad como consecuencia de la publicación de contenidos o de alguna otra conducta llevada a cabo a través de internet, puede presentar una única demanda ante los tribunales de cualquiera de los Estados competentes conforme a los artículos 5 y 6 . Esos tribunales serán competentes para decidir sobre la totalidad de los daños acaecidos en cualquier Estado y, aunque la Resolución no hace distinción entre unas u otras acciones, parece que también tendrán competencia para decidir sobre la rectificación o la retirada del contenido lesivo ${ }^{44}$.

89. El artículo 6 de la Resolución contempla la posibilidad de que las partes celebren acuerdos de elección del foro, estableciendo distintos requisitos según que se realicen con anterioridad o sean posteriores al acaecimiento del hecho generador del conflicto. Estos acuerdos no serán en absoluto habituales en este ámbito de la responsabilidad extracontractual.

90. A falta de sumisión, el artículo 5 de la Resolución atribuye la competencia internacional a los tribunales de los Estados en los que concurra alguno de los siguientes puntos de conexión: a) donde la persona cuya responsabilidad se reclama llevó a cabo la «critical conduct»; b) donde se encuentra el «home State» del demandado ${ }^{45}$; c) donde se hayan producido o puedan producirse la mayor parte de los daños («the most extensive injourious effects») y d) donde se encuentra el «home State» de la persona que haya sufrido o pueda sufrir los daños si el contenido publicado es accesible en ese Estado o la persona sufrió daño allí. En los dos últimos supuestos, la competencia queda excluida si el demandado demuestra que a) no obtuvo beneficio pecuniario ni otro tipo de beneficio significativo por el hecho de que el contenido publicado fuera accesible desde el Estado del foro $\mathrm{y} b$ ) una persona razonable no podía haber previsto que el contenido sería accesible desde el foro o que la conducta causaría un daño en ese Estado.

91. Una vez fijada la competencia de un tribunal conforme a los criterios anteriores, los demás tribunales tendrán que abstenerse de conocer de otras demandas referidas a los mismos hechos, conforme al artículo 3.2 de la Resolución. Con esta previsión se intenta poner freno a la regla del mosaico, es decir, se intenta evitar que se puedan interponer demandas referidas a la misma vulneración de los derechos de la personalidad ante los tribunales de cada uno de los Estados en los que el contenido lesivo resulte accesible. Y ello aunque esas demandas se limiten a reclamar por los daños sufridos únicamente en el territorio de ese concreto Estado.

92. Como complemento de lo anterior, si el tribunal ha fijado su competencia de conformidad con los criterios anteriores y ha determinado la ley aplicable al fondo de acuerdo con las previsiones de la Resolución, a las que se hará referencia en el siguiente apartado, la decisión de ese tribunal será reconocida y, en su caso ejecutada, en otros Estados si cumple los requisitos del Convenio de la Haya de 2 de julio de 2019 sobre reconocimiento y ejecución de sentencias extranjeras en materia civil o comercial. En este caso, la Resolución ha optado por hacer una remisión a un Convenio que, curiosamente, excluye de su ámbito de aplicación, en el artículo 2, la materia relativa a la difamación o a la protección de la vida privada.

${ }^{44} \mathrm{El}$ artículo 3, apartado 1, de la Resolución dispone: «A person who claims to have suffered or may suffer injury to rights of personality as a result of material posted on, or other activity conducted through the Internet, may file a single action in any one of the States referred to in Articles 5 or 6 against the person claimed to be liable for the injury and to seek redress for injuries that have occurred or may occur in all States».

${ }^{45} \mathrm{El}$ artículo 1, apartado 11, de la Resolución atribuye un significado distinto a los términos «home State» en función de que se refiere a una persona física o a una persona jurídica u otro tipo de entidad: "for natural persons, the State in which that person has his or her domicile or habitual residence» $\mathrm{y}$ "for persons other than natural persons, the State in which that person has its statutory seat or principal place of business, or under the law of which that person was incorporated or formed». 
93. En mi opinión, la supresión de la mera accesibilidad de los contenidos en línea como punto de conexión suficiente por sí solo para atribuir competencia internacional a los tribunales de un determinado Estado es un objetivo más que deseable. Sin embargo, la indefinición de algunos de los criterios que se establecen en la Resolución puede ser fuente de incertidumbre y reducir la eficacia de esta propuesta como vía para encontrar una solución de consenso que garantice la seguridad jurídica en esta materia. Así, sucede, por ejemplo, con la determinación de lo que ha de entenderse por «critical conduct» o con el significado de los términos «the most extensive injourious effects». Ni uno ni otro concepto se aclaran en la Resolución que se limita a remitir a la Ley del foro. Esta remisión supone un obstáculo para la interpretación uniforme de estos criterios de determinación de la competencia internacional ${ }^{46}$.

\section{El Derecho aplicable: la lex fori y sus excepciones}

94. La Resolución del IDI pretende también unificar los criterios en lo relativo a la ley aplicable para resolver las controversias sobre vulneración de los derechos de la personalidad por medio de internet. La exclusión de esta materia del Reglamento Roma II sobre la ley aplicable a las obligaciones extracontractuales tiene como consecuencia que sean las normas de conflicto del Estado cuyos tribunales tengan competencia las que den respuesta a esta cuestión y esto, obviamente, abre la puerta a múltiples soluciones en función del Estado donde se ha presentado la demanda.

95. El artículo 8 de la Resolución admite los acuerdos de elección de la ley aplicable tanto antes como después de surgida la controversia. Estos acuerdos previsiblemente tendrán una mínima o, incluso, nula incidencia práctica en este ámbito. Por ello, la norma fundamental es el artículo 7 en el que se regula la ley aplicable en función de cuál hubiera sido el criterio de determinación de la competencia internacional.

96. En defecto de elección, la regla general es la aplicación de la lex fori. Si la competencia se ha determinado conforme al criterio del lugar de la «critical conduct», se aplica sin más la lex fori. En todos los demás casos enumerados en el artículo 5, se prevén excepciones que permiten dejar de aplicar la ley del foro en favor de otras leyes como la del lugar que, considerando todas las circunstancias, presente los vínculos más estrechos con la situación, la ley del Estado donde tuvo lugar la «critical conduct»o la ley del Estado donde se han producido «the most extensive injourious effects». Por último, si la competencia se ha determinado en virtud de un acuerdo de sumisión de las partes y el tribunal designado no coincide con ninguno de los enumerados en el artículo 5, la ley aplicable será la del Estado que, considerando todas las circunstancias, presente los vínculos más estrechos.

97. La aplicación de la lex fori como criterio preferente resulta adecuada en una materia en la que está en juego la protección de derechos fundamentales y, precisamente por ello, hay una íntima vinculación con el orden público. Sin embargo, esta regla general está plagada de correctivos que permite aplicar una legislación distinta de la del foro y acudiendo a este fin a conceptos poco claros que no aparecen definidos en la propia Resolución ${ }^{47}$.

\footnotetext{
${ }^{46}$ Críticos con la caracterización de algunos de los criterios de conexión se muestran: P. M., DE Miguel AsENSIO, «La Resolución del IDI sobre internet y la vulneración de la privacidad. Tutela transfronteriza de los derechos de la personalidad ¿Hacia la armonización internacional? (A propósito de la Resolución del Institut de Droit International de 2019», Revista Espanola de Derecho Internacional, vol. 72/1, enero-junio 2020, p. 210 y A. LóPEZ-TARRUELLAS MARTínEZ, «Una visión crítica de la Resolución del IDI sobre internet y la vulneración de la privacidad desde el punto de vista del Derecho Internacional Privado de la Unión Europea», Revista Española de Derecho Internacional, vol. 72/1, enero-junio 2020, pp. 216 y sigs.

${ }^{47}$ En este sentido, P. M., DE Miguel Asensio, «La Resolución del IDI...», cit., p. 211, quien afirma lo siguiente: «...el art. 7 establece una estructura especialmente compleja con soluciones no exentas de dificultades. Por ejemplo, no queda claro por qué la ley aplicable ha de ser la del país en el que tuvo lugar la «critical conduct» del demandado incluso en situaciones en las que la información iba dirigida y produce efectos significativos únicamente en otros Estados. En la medida en que hay situaciones en las que la ley aplicable puede no ser la del foro, llama la atención que no se contemple el eventual recurso al orden público. La complejidad reseñada es de prever que limite la relevancia de la Resolución como modelo para los legisladores nacionales
} 
98. En definitiva, debe reconocerse el mérito de la propuesta del IDI en una materia en la que resulta patente la dificultad para alcanzar consensos ni siquiera en la Unión Europea. Sin embargo, la falta de claridad de algunos de los criterios utilizados para determinar la competencia internacional o la ley aplicable al fondo, así como la multitud de foros alternativos concurrentes suponen un límite a la virtualidad de la Resolución comentada como modelo para alcanzar una solución uniforme en la Unión Europea y mucho menos fuera de ella.

\section{A modo de conclusión}

99. A lo largo de las anteriores páginas se han podido constatar las dificultades para precisar el Estado cuyos tribunales tendrán competencia internacional en los litigios en materia de responsabilidad extracontractual por la vulneración de los derechos de la personalidad. A falta de normas específicas, es el artículo 7.2 del Reglamento Bruselas I bis la norma básica para determinar la competencia internacional en éste y en otros casos de responsabilidad extracontractual.

100. El TJUE ha ido interpretando o, más bien, complementando el fuero del lugar donde se hubiera producido o se pudiera producir el daño. Se trata de un fuero especial y alternativo al fuero general del domicilio del demandado. El Tribunal de Justicia ha reiterado en múltiples ocasiones que los fueros especiales han de ser objeto de una interpretación restrictiva. Sin embargo, la realidad muestra que la labor del máximo intérprete del Derecho de la Unión no ha sido precisamente la de restringir la noción de lugar del daño como criterio de fijación de la competencia internacional en los litigios por vulneración del derecho al honor, a la intimidad o a la propia imagen. Antes al contrario, el Tribunal de Justicia ha llevado a cabo una labor casi pretoriana mediante la que ha introducido fueros de competencia internacional que difícilmente pueden deducirse del tenor de la norma.

101. Esta labor «creativa» se ha sentido especialmente en los casos más complejos en los que la lesión del derecho al honor, a la intimidad o a la propia imagen se ha llevado a cabo por el medio virtual con un alcance potencialmente universal de la difusión de los contenidos lesivos. En este contexto, la víctima puede elegir entre una multitud de foros de competencia internacional alternativos o concurrentes, algunos con distinto alcance que otros. La competencia del tribunal se extenderá también a la demanda reconvencional cuando se derive del mismo hecho en el que se fundamenta la demanda principal ${ }^{48}$

102. Dejando al margen la posibilidad de sumisión de las partes, que tiene una importancia residual en este ámbito. El perjudicado podrá ejercitar acciones para instar la indemnización de la totalidad de los daños y perjuicios sufridos en cualquier Estado o para lograr la retirada o rectificación del contenido difamatorio o lesivo de la intimidad ante los tribunales del Estado del domicilio del demandado,

y regionales, al tiempo que la indefinición respecto de algunos de los criterios de conexión menoscaba su potencial armonizador». También se muestra crítico con las soluciones propuestas, A. López-TARRUELLAS MARTínEZ, «Una visión crítica...», cit., pp. 219 y 220.

${ }^{48}$ Así lo dispone el apartado 3 del artículo 8 del Reglamento Bruselas I bis. El TJUE ha tenido ocasión de pronunciarse sobre esta cuestión en la STJUE de 31 de mayo de 2018, asunto Éva Nothartová c Sámson József Boldizsár, C-306/17, ECLI:EU:C:2018:360. Los hechos de los que esta Sentencia trae causa son a grandes rasgos los siguientes: La Sra. Nothartová, con residencia en Eslovaquia, presentó ante el órgano jurisdiccional remitente, el Tatabányai Törvényszék (Tribunal General de Tatabánya, Hungría), una demanda contra el Sr. Boldizsár, con residente en Hungría, por considerar vulnerados sus derechos de imagen al haber sido fotografiada y grabada en vídeo sin su consentimiento y difundir posteriormente ese material por medio de internet. A su vez, el demandado en el litigio principal interpuso una demanda reconvencional de indemnización por considerar que la demanda inicial tenía por efecto restringir la difusión de sus creaciones intelectuales en el sitio YouTube.

El Tribunal remitente cuestiona su competencia para conocer de la demanda reconvencional. El TJUE responde que el artículo 8.3 del Reglamento Bruselas I bis se aplicará en este caso, aunque no con carácter exclusivo, para fundar la competencia internacional del órgano jurisdiccional que conoce de la demanda principal «siempre que el examen de esta demanda reconvencional exija que ese órgano jurisdiccional aprecie si son o no lícitos los hechos en los que el demandante basa sus propias pretensiones». 
como fuero general, o ante los tribunales del Estado donde se originó la conducta lesiva. Ambos fueros de alcance general se aplican con independencia de que el medio empleado para la difusión del contenido lesivo haya sido internet o cualquier otro como la prensa escrita, la radio o la televisión.

103. En el evento de que el contenido atentatorio contra los derechos de la personalidad se hubiera producido a través de internet, y solo en este caso, la víctima cuenta con un fuero adicional basado en el lugar del daño y también con un alcance general: el Estado del centro de intereses de la persona física o jurídica que hubiera sufrido los daños. La delimitación de ese centro de intereses puede, a su vez, conducir a una diversidad de Estados competentes. Así, en el caso de una persona física puede tener su centro de intereses en el Estado donde se encuentre su residencia habitual o donde desempeñe su actividad profesional o en cualquier otro Estado con el que tenga un «vínculo particularmente estrecho». Si se trata de una persona jurídica su centro de intereses estará en el Estado en el que ejerce la parte esencial de su actividad económica. Nada ha dicho el TJUE de momento sobre cuál será el centro de intereses en el caso de personas jurídicas o entidades cuya actividad principal no tiene un contenido económico, así una entidad sin ánimo de lucro.

104. A estos fueros de alcance general, hay que sumar otro de ámbito más limitado y aplicable también con independencia del medio de difusión empleado. Me refiero a cada uno de los Estados donde se ha manifestado el daño para la víctima, que serán competentes para decidir exclusivamente sobre los daños acaecidos en su respectivo territorio. En el caso de que la difusión se haya producido por medio de internet, esta regla del mosaico conduce a una multitud de Estados con competencia internacional y da vía libre al peregrinaje jurisdiccional de la víctima ante los tribunales de cada uno de los Estados en los que la información sea o haya sido accesible.

105. Se puede concluir, pues, que la labor «creativa» llevada a cabo por el TJUE en la interpretación del fuero del lugar del daño en materia de vulneración de los derechos de la personalidad ha creado una especie de «macrofuero» que no parece coherente ni con la buena administración de justicia ni con la previsibilidad de las normas de competencia. Máxime cuando la fijación de la competencia internacional es determinante también de la ley aplicable para resolver sobre el fondo, ante la ausencia de normas de conflicto unificadas. 